\title{
Improper management of dams constructed with local materials, infiltration risk and wasted electric energy
}

\author{
Victorita Radulescu* \\ Department of Hydraulics, Hydraulic machinery and Environmental Engineering, Faculty of Energy, \\ University Politehnica of Bucharest, Splaiul Independentei 313, Sector 6, Bucharest, Romania
}

\begin{abstract}
The present paper presents a study case of improper dike rehabilitation and inefficient management of the water volume from two hydropower lakes, with dams built with local materials. In Romania, with its high hydrographic potential, this solution was adopted for construction of more than 600 hydropower plants, many of them now confronted with infiltration and erosion, and appeared into lateral sides of the dikes. The paper covers some theoretical and practical aspects referring to the functioning of hydropower lakes, establishing the cross-sections with problems in exploitation. Reduced water level produces less electric energy than initially estimated. The dam's construction was not correlated with the geomorphologic conditions and climatic parameters, being necessary supplementary measurements and data acquisition to calibrate the numerical model. There are mentioned some considerations referring at the mathematical model, based on new hypotheses of infiltration through sediments with different dimensions and characteristics. The flow through dikes is assumed non-permanent due to massive infiltration. Part of the numerical modeling, the obtained velocities of infiltration, and the streamlines are illustrated. The results of the tested solution prove its efficiency and allow illustrating and some other sections with possible risk in functioning. Some discussions, conclusions, and references are finally presented.
\end{abstract}

\section{Introduction}

It must be mentioned that nowadays, nationwide, there are 636 dams constructed realized from local materials, among which the analyzes made in the last four years have revealed a number of shortcomings, as follows:

- 134 dams have concrete damaged tiles;

- 69 dams present infiltration into the dam's body and into the lateral dikes;

- 143 dams have erosion through dams at access roads and pears;

- 186 dams have blocked the bottom of the emptying zone with major defects in the water discharge area, or are not equipped with surge arresters surfaces;

- 21 dams have flaws nowadays not functional;

\footnotetext{
*Corresponding author: vradul4@gmail.com
} 
- 35 dams have the basin's reservoirs filled with sediments, with $60 \%$ clogging rate;

- 63 dams are abandoned, without legal documentation;

- 5 dams are proposed to be listed for abandonment in near future [1].

One of the most serious problems mentioned before is the infiltration through dams and dikes, the erosion through dams, access roads, breaches in dams and the clogging of lakes [1]. From all the mentioned hydropower systems, about 270 have major problems.

These issues have diminished the payload, with immediate effect a decreasing of the produced electricity. A report of the appeared problems for some dams is presented in Table 1.

Table 1. The actual situation of the dams with problems in Romania.

\begin{tabular}{|c|c|c|c|c|c|c|c|c|c|}
\hline HB & ND & DT & I & ESP & PD & DD & CL & A & D \\
\hline Someş - Tisa & 33 & 21 & 5 & 3 & 3 & 0 & 1 & 0 & 0 \\
\hline Crişuri & 31 & 6 & 4 & 9 & 22 & 0 & 0 & 0 & 0 \\
\hline Mureș & 10 & 6 & 0 & 1 & 1 & 1 & 1 & 0 & 0 \\
\hline Banat & 1 & 0 & 0 & 0 & 0 & 0 & 1 & 0 & 0 \\
\hline Jiu - Dunăre & 4 & 0 & 0 & 1 & 1 & 0 & 2 & 0 & 0 \\
\hline Olt & 45 & 19 & 6 & 8 & 11 & 0 & 1 & 1 & 0 \\
\hline Argeş - Vedea & 119 & 24 & 18 & 43 & 29 & 0 & 0 & 1 & 4 \\
\hline Buzau-Ialomita & 28 & 0 & 0 & 3 & 17 & 0 & 0 & 7 & 1 \\
\hline Siret & 76 & 15 & 17 & 2 & 23 & 0 & 9 & 19 & 0 \\
\hline Prut - Bârlad & 285 & 43 & 19 & 71 & 79 & 20 & 18 & 35 & 0 \\
\hline Dobrogea - Seaside & 4 & 0 & 0 & 2 & 0 & 0 & 2 & 0 & 0 \\
\hline TOTAL & 636 & 134 & 69 & 143 & 186 & 21 & 35 & 63 & 5 \\
\hline
\end{tabular}

Where: HB- Hydrographic Basins, ND- Number of Dams, DT- Damaged Tiles, IInfiltration, ESP- Erosion Slopes Pears, PD- Problem Discharging, DD- Damaged Dams, CL- Clogged Lakes, A- Abandoned, D- Decommissioning

The analyzed dams, confronted with infiltration problems in this paper are located on river Crisul Repede on the western slopes of the Apuseni Mountains.

\section{Calibration, elaboration of the initial experimental database}

The physical and geographical natural unit traversed, the terrain, and the morphological structure of the sediments are conditions of water distribution and the flow regime for the rivers from the basin Cris.

These sediments are the main resource of dams structure. The Apuseni Mountains are distinguished by a greater amount of rainfall compared to other regions with similar altitudes in Romania, due to the west exposure. The average value of precipitation is over $1400 \mathrm{~mm} /$ year. In the proximity of the analyzed lakes, it can reach at $30-35 \mathrm{l} / \mathrm{s} / \mathrm{km}^{2}$, due to the mentioned amount of rainfall, sharp slopes of drain zone, and the petrographic substrate, generally impermeable.

Since the commissioning, the level of the free surface in these two cascade lakes was reduced with $8 \mathrm{~m}$ and $9 \mathrm{~m}$ respectively, due to permanent infiltration through dikes. As immediate effect was, less electric energy produced. Under these circumstances, the lakes are not able to manage the excess of water appeared during floods as it was in 1999, 2000, 2001, 2002, 2005, 2008, and 2012 (years 2005 and 2008 with massive floods). The maximum flow rate, with $1 \%$ insurance can be achieved in Oradea on Crisul Repede, at 970 $\mathrm{m}^{3} / \mathrm{s}$ and the minimum value, with $80 \%$ insurance (period of April-November) at $1.60 \mathrm{~m}^{3} / \mathrm{s}$. Some of the registered data are presented in Table 2.

The annual average flow of alluvial deposits in suspension is $3.5 \mathrm{~kg} / \mathrm{s}$ into the post Salard, $7.5 \mathrm{~kg} / \mathrm{s}$ in Oradea and $6 \mathrm{~kg} / \mathrm{s}$ in Zerind post. 
Table 2. Water flow rate required to be transported through lakes.

\begin{tabular}{|c|c|c|c|}
\hline Hydro station & $\begin{array}{c}\text { Main Flow rate } \\
\left(\mathbf{m}^{3} / \mathbf{s}\right)\end{array}$ & $\begin{array}{c}\text { Minimum Flow rate } \\
\left(\mathrm{m}^{3} / \mathbf{s}\right)\end{array}$ & $\begin{array}{l}\text { Maximum Flow } \\
\text { rate }\left(\mathrm{m}^{3} / \mathrm{s}\right)\end{array}$ \\
\hline Vadu Crisului & 19,60 & $0,71 / 24.11 .1972$ & 780/04.2005 \\
\hline Oradea & 23,10 & $0,81 / 19.12 .1953$ & $820 / 04.1932$ \\
\hline
\end{tabular}

The specific annual average leakage of silt in suspension is below 0.5 tons/ha /year in the flat regions and between 0.5- 1.0 tons/ha/year in the hills and mountains with low altitudes. The higher values of leakage in hillside areas can be explained by the presence of the petrographic layer, easier to be eroded. In Table 3 are presented the most important climatic data and in Table 4 the main characteristics of the lakes.

Table 3. The climatic data.

\begin{tabular}{|c|c|}
\hline Average annual precipitation & Mountain area $-1600 \mathrm{~mm} /$ year \\
\cline { 2 - 2 } Average temperature & Hill area $-550-600 \mathrm{~mm} /$ year \\
\hline & Mountain area $-4^{0} \mathrm{C}$ \\
\cline { 2 - 2 } & Hill area $+10^{0} \mathrm{C}$ \\
\hline
\end{tabular}

Table 4. The main characteristics of lakes.

\begin{tabular}{|c|c|c|c|c|}
\hline Lakes & $\begin{array}{c}\text { Volume } \\
\left(\mathbf{m i l . ~}^{\mathbf{3}}\right)\end{array}$ & $\begin{array}{c}\text { Used flow } \\
\left(\mathbf{m}^{\mathbf{3}} / \mathbf{s}\right)\end{array}$ & $\begin{array}{c}\text { Discharged } \\
\left.\text { Flow } \mathbf{~ m}^{\mathbf{3}} / \mathbf{s}\right)\end{array}$ & $\begin{array}{c}\text { Bottom } \\
\text { drain }\end{array}$ \\
\hline Lake 1 & 33768 & 12,3 & 0,1 & 2 \\
\hline Lake 2 & 44039 & 10,1 & 0,14 & 2 \\
\hline
\end{tabular}

The values mentioned in Table 4 were determined by the National Authority "Apele Romane - Cris", in collaboration with the Environmental Protection Inspectorate Bihor. Consequently, the development of the hydropower system realized along the river Crisul Repede has been finished with the construction of 7 hydropower plants with an installed power of $208 \mathrm{MW}, 5$ dams, and over $34 \mathrm{~km}$ of main and secondary headrace. The dam's realization was accomplished in ' 80 , followed shortly by infiltration through dikes. In Figure 1 are presented the appeared infiltration.

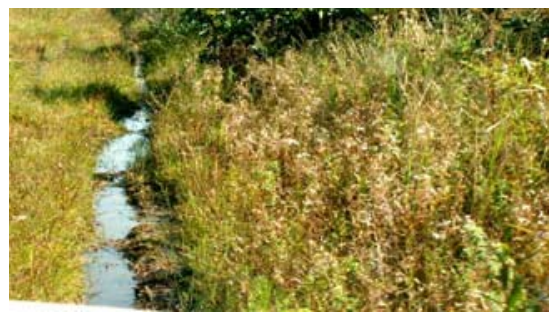

a

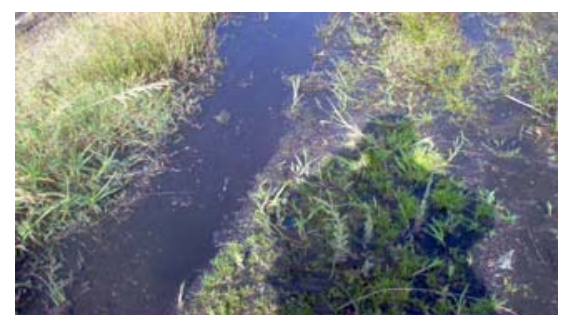

b

Fig. 1. Infiltration through dikes, a - Lake 1, b - Lake 2.

Due to permanent infiltration, new analysis and rehabilitation are necessary. The purpose of this paper is to establish the actual cross-sections with problems when the lakes are full of water, responsible for infiltration and, if possible to determine also the future risk zones.

\section{Mathematical model}

Starting from the general equations for underground flow, deduced from the general flow motion for a real fluid [2]: 


$$
\frac{d v_{x}}{d t}=X-\frac{1}{\rho} \frac{\partial p}{\partial x}+R_{x} ; \quad \frac{d v_{y}}{d t}=Y-\frac{1}{\rho} \frac{\partial p}{\partial y}+R_{y} ; \quad \frac{d v_{z}}{d t}=Z-\frac{1}{\rho} \frac{\partial p}{\partial z}+R_{z}
$$

Where $v_{x}, v_{y}, v_{z}$ are the velocity components, $X, Y, Z$ the components of the unitary mass force, and $R_{x}, R_{y}, R_{z}$ the components of the friction force on the mass unit, we may deduce the velocity for the underground flow.

If the mass forces are only the gravity, $X=0, Y=0, Z=-g$, and introducing the hydraulic load $h=z+\frac{p}{\gamma}$ the equations (1) become:

$$
\frac{d v_{x}}{d t}=-\frac{\partial h}{\partial x} ; \quad \frac{d v_{y}}{d t}=-\frac{\partial h}{\partial y} ; \quad \frac{d v_{z}}{d t}=-g \frac{\partial h}{\partial z}
$$

For the underground unsteady flow [3], the velocity components are deduced from the Darcy's Law, where $\mathrm{k}$ is the permeability:

$$
v_{x}=-k \frac{\partial h}{\partial x} ; \quad v_{y}=-k \frac{\partial h}{\partial y}
$$

Based on continuity equation for the considered volume, the Boussinesq equation became:

$$
-\frac{\partial}{\partial x}\left(H k \frac{\partial h}{\partial x}\right)-\frac{\partial}{\partial y}\left(H k \frac{\partial h}{\partial y}\right)+m \frac{\partial H}{\partial t}-\varepsilon=0
$$

Where is the flow rate that supplies from the free surface the underground flow [4], $H$ the distance between the impermeable layer and selected area for calculation from the underground water surface, and $m$ the porosity. In Figure $2 \mathrm{a}$ are presented the main parameters, and in Figure $2 \mathrm{~b}$ the main aspect of the underground water flow through the dike.

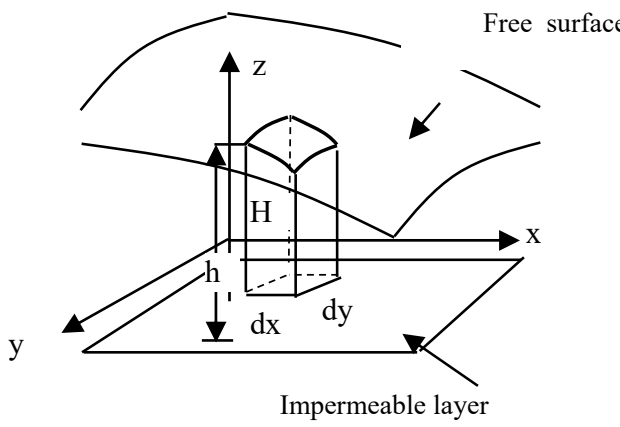

a

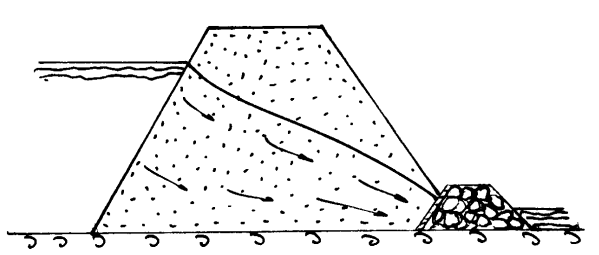

b

Fig. 2. The scheme of underground water flow.

The double/multiple porosity model is a quite flexible tool to treat cases where a porous matrix and one or more families of continuously distributed fractures are present. It is supposed that the Reynolds number in porous spaces is small enough so that the non-linear terms in the Navier-Stokes equations can be neglected. The model was for the first time described for fractured rocky aquifers with a porous matrix, by assuming two pressure fields locally (one for pores and one for fractures) as well as the validity of Darcy's law in 
each space. The exchange of pore fluid between the two spaces was taken to be proportional to the corresponding pressure drop.

To reduce the effect of the appeared erosion in the sheeting of concrete from the lateral channel, 4 years ago were constructed supplementary screens, for protection. Shortly appears infiltration, Figure 3-a followed by local erosion and cracks of the concrete or clogging, Figure 3-b.

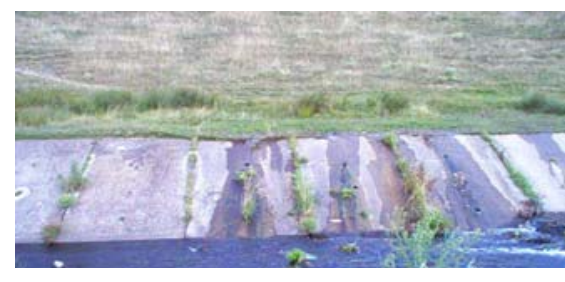

a

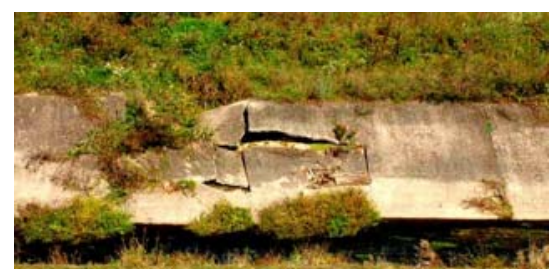

$\mathrm{b}$

Fig. 3. New appeared problems: a - Massive infiltration $b$ - Cracks in the concrete.

For modeling the underground flow under the concrete was used the method of complex potential. If it is assumed a plane potential flow motion in a cross-section of the dikes, may be used the complex variable functions.

Based on local measurements was established the dike profile in cross-sections, the nature, and porosity of the material. Because is free level on both sides of the dam sealing [5], a special problem is represented by the estimation of the underground water curve, as in Figure 2-b.

For the numerical modeling are several types of boundary conditions were considered:

- The impermeable frontier is a streamline (as example for the bedrock);

- The depression curve, Figure 2-b, is considered also an upper streamline; on this surface, the pressure is equal to the atmospheric pressure;

- The frontiers in contact with the water, as contact borders (the upstream and downstream); on these areas the pressure varies according to the hydrostatic law pressure;

- face runoff; in this case, the pressure is equal to the atmospheric pressure [6,7].

\section{Numerical modeling and the obtained results}

It was analyzed the stability of the dikes from a hydropower plant constructed with local materials, situated in the zone of deviation. The underground phenomena will reveal the influence of the basic sediments material on the dikes stability.

The mathematical model of the hydrodynamic phenomena and the stability analysis were performed in seven sections with different granulometry and permeability.

The mathematical model was tested with MODFLOW, for underground flow, studied in 3D, with the supplementary module of particles transport PMPATH, used to solve the differential equations.

It was modeled the seepage through embankments on both sides, but for the presentation was selected only the right side, which is more damaged.

Consequently, for each studied case, under the previous considerations, are set three levels of water in the lake and different permeability coefficients, based on local measurements.

The cross-sections considered at risk in the transport of the tributary flows are selected from the sections mentioned in Table 5 .

The rate flow considered, responsible for actual situation is:

- the attention flow $Q=290 \mathrm{~m}^{3} / \mathrm{s}$; 
- the flood flow, $\mathrm{Q}=472 \mathrm{~m}^{3} / \mathrm{s}$;

- the flow of danger: $\mathrm{Q}=567 \mathrm{~m}^{3} / \mathrm{s}$.

Table 5. The analyzed sections and their length.

\begin{tabular}{|c|c|c|c|c|c|}
\hline Section type & $\begin{array}{c}\text { Length } \\
\text { on top }\end{array}$ & $\begin{array}{c}\text { Up } \\
\text { stream }\end{array}$ & \multicolumn{2}{|c|}{$\begin{array}{c}\text { Down } \\
\text { stream }\end{array}$} & \multicolumn{2}{|c|}{$\begin{array}{c}\text { Applied length }[\mathbf{m}] \\
\text { Left } / \text { Right size }\end{array}$} \\
\hline $\mathbf{1 5 m}<\mathbf{H}<\mathbf{2 7 m}$ & 6,00 & 0,48 & 0,08 & 2627 & 1827 \\
\hline $\mathbf{7 . 5 m}<\mathbf{H}<\mathbf{1 5 m}$ & 6,00 & 390 & 255 & 2700 & 3600 \\
\hline $\mathbf{2 . 5}<\mathbf{H}<\mathbf{7 . 5 m}$ & 4,00 & 0,18 & 0,02 & 1850 & 1050 \\
\hline $\mathbf{H}<\mathbf{2 . 5}$ & 4,00 & 13 & 8 & 890 & 546 \\
\hline & & & Total length & $\mathbf{8 0 6 7}$ & $\mathbf{7 0 2 3}$ \\
\hline
\end{tabular}

There are analyzed two cases of cross-sections considered significant, discretized in finite elements:

- Case A- with mud lens and screen of protection partially embedded in bedrock;

- Case B - without a screen of protection (as it is nowadays on the right side in Lake 1).

Each color is associated with a specific permeability. The numerical modeling confirms the measurements. The downstream shore is discontinuous, consisting of fine sand, medium rare gravel, sandy clay loam sands-profit, lens mud, and vegetal elements.

The material structure is bedrock with alternative marl, clay marl, and tuff fine sands. The dam is filled with local material, being of two types:

- type I, a material less permeable, made up of ballast and ballast mixed with sterile, proportion 2: 1, used in the core, trapezoidal large-section;

- type II, a material more permeable, made up of clean ballast, used on the periphery of the nucleus from the type I, for upper side, front and foundations.

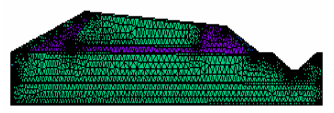

a

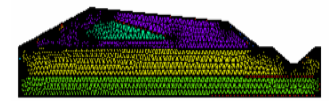

$\mathrm{b}$

Fig. 4. The dam discretization in cross-sections, a- Case A and b - Case B.

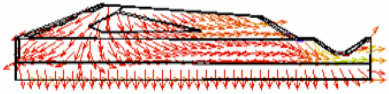

a

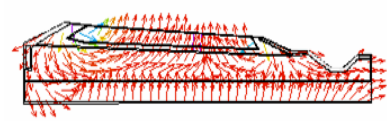

b

Fig. 5. Distribution of velocity through dikes, a - Case A and b - Case B.

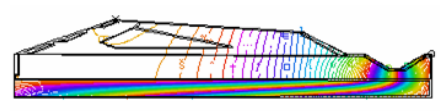

a

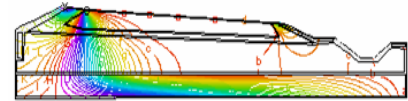

b

Fig. 6. The stream lines in cross-sections, a - Case A and b - Case B.

First was modeled the effect of the imperfect screen, because it was realized in an area of closure of the natural bed, which do not fit perfectly in bedrock. The underground hydrodynamic flow was modeled with successive steps by increasing the permeability coefficient in the areas where the hydraulic gradients exceed the allowable values. By local measurements was determined in 7 places the occurrence of the muddy lens compacted, with low permeability [8]. Their position was specified by geological correlations and their permeability was chosen correspondingly, $\mathrm{k}=10^{-5} \mathrm{~cm} / \mathrm{s}$. 
There are zones with streamlines concentration, so the local speeds are quite high, making possible the transport and for others particles, with larger sizes.

It was also considered the effect of the rainfall, with a medium value of $10-20 \mathrm{~mm}$ and the drainage factor of $15 \%$. It brings a supplementary contribution to the output gradients, but the depression curve does not change fundamentally. The changes in the hydraulic gradient distribution from the dam structure, and sometimes the local concentration of the streamlines and additional spacing in other areas proved that there are zones inside the dam with infiltration and erosion and areas with sedimentation and clogging. The dam's behavior, a consequence of the improper execution has as result in decrease of the free surface water level, as to maintain and control the infiltration, in both lakes with $8 \mathrm{~m}$ and 9 $\mathrm{m}$ respectively. The negative effect is summarized in Table 6 .

Table 6. The actual situation in analyzed lakes.

\begin{tabular}{|c|c|c|c|c|}
\hline Lakes & Situation & $\begin{array}{c}\text { Volume } \\
\left(\text { mil. m}^{3}\right)\end{array}$ & $\begin{array}{c}\text { Area } \\
\text { (ha) }\end{array}$ & $\begin{array}{c}\text { Produced energy } \\
\text { (MW) }\end{array}$ \\
\hline \multirow[t]{2}{*}{ Lake 1} & initial & 52,768 & 605,7 & 30 \\
\hline & actual & 41,810 & 520,3 & 18 \\
\hline \multirow[t]{2}{*}{ Lake 2} & initial & 44,039 & 510,1 & 30 \\
\hline & actual & 30,420 & 408 & 18 \\
\hline
\end{tabular}

\section{Conclusions}

The non-uniformity of the used material, the screens performed incorrectly, or with major cracks with improper embedding in bedrock, the presence of the irregular lenses of mud in the base material of the dams, and the irregular shore of concrete, has as result apparition of preferential areas of water circulation through dikes and dams.

The obtained numerical results confirm the reality, massive infiltration and supplementary, pointed some new sections with future risk of erosion. The existence of some large fractions of material ensures some stability in the global and local pier. The spectrum obtained presents a hydrodynamic lift, irregular of the depression curve depending on the configuration and spatial distribution of the muddy lens. By analyzing the critical gradients values obtained by numerical modeling, it is obviously evident that nowadays are met the conditions to move fine fractions of sediments, both at entry and exit. An additional screen embedded in bedrock is the only possible solution.

\section{References}

1. M. B. Allen, B. Murphy, Water Resources 22 (1996)

2. I. Seteanu, V. Radulescu, N. Vasiliu, D Vasiliu, Mecanica fluidelor, Fundamente si Aplicatii, (Editura Tehnica, Bucharest, 1998)

3. V. Radulescu, V. Nistreanu, Sisteme hidraulice de Aductiune. Fundamente, Calcul, Exemple, Seria Hidraulica (Editura Bren, Bucuresti, 2004)

4. V. Radulescu, Conference FEDCSIS, Prague, Czech Republic (2017)

5. N. Zhiguo, L. Ju, R. You, Procedia Engineering, 15 (2011)

6. I. Valgma, H. Torn, K. Erg, Oil Shale, 23, 1, (Estonian Academy Publishers, 2006)

7. V. Radulescu, Conference SIELMEN, Chisinau (2017)

8. U.F.A. Karim, Q.T. Tran, R. Van der Meij, Geotechnical Engineering for Infrastructure and Development, ICE Virtual Library (2015) 